\title{
Optimal Taxation of Married Couples with Household Production
}

\author{
Henrik Jacobsen Kleven and Claus Thustrup Kreiner*
}

Received 13 October 2005; in revised form 24 January 2007; accepted 15 May 2007

The literature suggests that the concern for economic efficiency calls for individualbased taxation of married couples with a higher rate on the primary earner. This paper reconsiders the choice of tax unit in the Becker model of household production. In the absence of restrictions on the use of commodity taxes, efficient taxation requires joint taxation of the family. In the presence of restricted commodity taxation, the income tax should compensate for the erroneous commodity taxes. In this case, individual taxation is typically optimal, but not necessarily with a higher rate on primary earners as usually suggested.

Keywords: optimal taxation, married couples, home production

JEL classification: H 21, D 13, J 22

\section{Introduction}

Whether married couples should be subject to joint or individual filing has been a debating point throughout the existence of the income tax. Since the papers by Rosen (1977) and Boskin and Sheshinski (1983), an efficiency argument for individual taxation has been widely accepted. In this paper, we consider the robustness of their argument to the introduction of household production in the analysis.

The argument for individual taxation starts with the empirical observation that the labor supply of primary earners is less elastic than that of secondary earners. Traditional Ramsey considerations call for a higher tax rate on the less elastic tax base, implying that the income of primary earners should carry a relatively high rate. This goal can be achieved by a progressive individual-based income tax, since the primary earners have a higher income and therefore face a higher marginal tax rate than the secondary earners under such a system. By contrast, a fully joint income tax generates identical

* We wish to thank Birgit Grodal, Wolfram F. Richter, Peter Birch Sørensen, Ray Rees, and two anonymous referees for helpful comments. This research project is supported by a grant from the Danish Economic Policy Research Network. 
marginal tax rates for the two spouses and hence does not meet the Ramsey efficiency principle.

Despite the important role of the labor supply for the above result, little attention has been paid to the model of labor supply on which it is based. The literature on optimal income taxation relies on the labor-leisure framework, in which households are assumed to derive utility from the consumption of market goods and time, separately. However, since the work of Becker (1965) it has been recognized that goods and time are not themselves carriers of utility, but are rather inputs into a process that generates household activities or commodities. In other words, households derive utility from different combinations of goods and time, and there is no such thing as pure leisure. For example, watching a movie requires not only the moviegoer's time, but also the purchase of transportation, tickets, etc. One may think of this as a theory of consumption technology or as a theory of household production, although it does not deal with production activities in the common sense of the term.

Our paper builds upon the Becker (1965) framework, extended to allow for the presence of two members of each household. In this framework, the taxation of labor income distorts behavior in two ways. First, income taxation lowers shadow wages within the household, inducing a substitution away from goods-intensive activities towards time-intensive activities. As a result, more time is spent in the household and less time in the market, consistent with the labor-leisure distortion in a standard model. Second, if the income tax system involves differential rates for the husband and wife, it affects the relative shadow wage in the family. This creates a distortion in the primary-secondary input ratio in household activities. In other words, income taxation may involve a composition effect on nonmarket time, in addition to the more traditional level effect. The design of the tax system should take account of both of these distortions. We analyze whether this calls for individual or joint income taxation, taking into account that governments also have commodity taxes at their disposal. The paper should be seen as an extension of Kleven's (2004) analysis of optimal commodity taxation in the Becker model. By considering only single-person households, he was unable to deal with the issue of optimal versus joint income taxation.

Our first result is that in the absence of restrictions on the use of commodity taxes, joint filing is optimal. The result applies also in the presence of different labor-supply elasticities for primary and secondary earners. Although individual taxation can be used to increase the labor supply in this case, it is an inefficient way to deal with the distortion of time allocation in the Becker model. Since the distortion against market time (labor supply) reflects a distortion of household activities, and since these activities use market-produced goods, we may take care of the labor-supply distor- 
tion more directly through the use of selective commodity taxation. Once the optimal commodity tax system is in place, the income tax system should avoid distorting the time inputs of the two spouses in household activities. This requires identical marginal tax rates for the husband and wife, which is achieved by joint income taxation.

This implies that the case for individual taxation should be sought in the presence of nonoptimal commodity taxes. This is of course quite realistic. In practice, there are important restrictions on the implementation of optimal commodity taxes, resulting from administrative costs, lack of information, and political inefficiencies. Our second result deals with the case of such restrictions. Now the income tax should try to compensate for the erroneous commodity taxes. We show that the ability of individual income taxation to do so requires a systematic relationship between the primary-secondary input ratio and the activities that are taxed too little or too much. In particular, if the time of primary earners is used predominantly in those activities that are favored by commodity taxes, we should impose a relatively low tax rate on primary earners, and mutatis mutandis. On the other hand, if there is no such correlation, it is still optimal to employ joint taxation. In any case, the optimal income tax system depends on the nature of the restrictions on commodity taxes, not the magnitude of labor-supply elasticities.

The paper is related to the study by Piggott and Whalley (1996), who were first to point out that individual-based taxation distorts input ratios in household production. Using a general-equilibrium model calibrated to Australian data, they showed that the costs of the household production distortion can outweigh the benefits from setting different tax rates on spouses to reflect labor-supply elasticities. Hence, welfare gains can occur under switches from individual to joint income taxation. But as pointed out by Apps and Rees (1999a) and Gottfried and Richter (1999), it is important to keep in mind that Piggott and Whalley were comparing joint taxation with an existing tax structure, which involved individual-based but nonoptimal income tax rates. Even in the Piggott-Whalley setup, fully joint taxation is an unlikely candidate for the optimal tax system.

Our contribution to the literature is twofold. First, we wish to study the sensitivity of results to the specification of household production. Whereas the existing analyses rest on the simplified Gronau $(1973,1977)$ setup - retaining the assumption of pure leisure as a utility-yielding commodity - we adopt instead the Becker framework. As suggested above, we find that the chosen specification can be very important for the policy conclusions. Second, we study the relation between the choice of tax unit and the presence of administrative or other restrictions giving rise to nonoptimal commodity taxes. Implicitly, since the previous models operated with just one marketproduced consumption good, they studied the issue under an assumption 
of optimal commodity taxation. We show that restrictions on commodity taxation are important, because the income tax then needs to allow for distortions in commodity demand, in addition to distortions in time allocation.

Before proceeding to the theoretical analysis, a few comments about its limitations are warranted. Like the authors of previous papers on this topic, we consider only linear taxation of couples. This makes the problem formally identical to a Ramsey optimal-tax problem, simplifying the analysis a great deal. However, because of the linearity assumption, the income tax system is effectively an individual-based tax, although gender/spouse-specific. By implication, the issue in this literature is really one of uniform versus differentiated marginal tax rates on spouses, rather than the more complex issue of individual versus joint tax treatment. In general, a joint income tax is one with an interdependence between the tax payment of one earner and the earnings of his/her spouse. One could in fact incorporate selective income tax rates in a framework of joint filing, just as one can have identical marginal tax rates with individual-based taxation. Despite these considerations, the present paper adopts the conventional terminology that individual-based taxation corresponds to differentiated tax rates, whereas joint taxation involves uniform tax rates. For an analysis of a fully general nonlinear income tax for couples (without household production), we refer to Kleven, Kreiner, and Saez (2006).

Our analysis does not incorporate distributional concerns. The purpose here is not to characterize optimal redistribution, but simply to reconsider the Ramsey efficiency argument for individual-based taxation. Before making firm policy recommendations, one should of course consider that the choice of tax unit may raise issues pertaining to distribution both across families and across spouses within families. Kleven et al. (2006) presents a comprehensive study of optimal interfamily redistribution, and Apps and Rees (1999b) incorporate both intra- and interfamily distributional concerns into their analysis.

We adopt the standard household utility function (unitary) approach regarding the family as an income pooling unit. This model is formally equivalent to a single decisionmaker optimizing labor supply along two dimensions, and there is no conflict about decisions within the family. We adopt the unitary model because of its simplicity, and because the Boskin-Sheshinski efficiency argument for individual taxation was based on that model.

It is well known that the income-pooling assumption is inconsistent with empirical evidence (Lundberg, Pollak, and Wales, 1997). It is therefore important to note that our results can be generalized to the collective laborsupply model modeling the couple as two separate utility-maximizing individuals engaging in Pareto-efficient bargaining (as in Chiappori, 1992). This is due to the fact that in any model with optimizing individuals/households 
and efficient markets - including the unitary and the collective models the marginal excess burden of taxation is given by the behavioral effects on government revenue (e.g., Kleven and Kreiner, 2005). Thus, while the choice between these two models can have implications for the labor-supply functions of husband and wife, the modeling choice will not affect the optimal Ramsey tax formulas as functions of labor-supply elasticities. This argument applies only to collective models where the intrahousehold allocation is Pareto-efficient. The introduction of inefficient bargaining would, of course, give an argument for a Pigouvian-type tax in order to counteract the distortion in household decisionmaking. This effect on economic efficiency is, however, quite different from the standard Ramsey tax problem studied in this paper. ${ }^{1}$

The paper is organized in the following way. The next section sets up the model of household production, and section 3 shows that the fully optimized tax system involves joint taxation. Section 4 analyzes optimal income taxation with restrictions on the use of commodity taxes, and section 5 discusses the specification of household production functions. Section 6 investigates the role of labor-supply elasticities for our results, and section 7 concludes.

\section{The Model}

The representative family obtains utility by combining market-produced goods $X^{1}, X^{2}, \ldots, X^{n}$ and household time $L^{1}, L^{2}, \ldots, L^{n}$ so as to obtain commodities/activities $Z^{1}, Z^{2}, \ldots, Z^{n}$. That is,

$$
U=U\left(Z^{1}, Z^{2}, \ldots, Z^{n}\right), \quad Z^{i}=f^{i}\left(X^{i}, L^{i}\right), \quad i=1, \ldots, n,
$$

where the $f$-functions exhibit constant returns to scale. ${ }^{2}$ This basic setting is identical to the original Becker (1965) framework except that $L^{i}$, rather than being the input of one individual, is treated as a composite input due to the presence of two members of each household. Thus,

$$
L^{i}=g^{i}\left(L_{P}^{i}, L_{S}^{i}\right), \quad i=1, \ldots, n,
$$

1 Moreover, it is not clear that a noncooperative model with household inefficiency would deliver more realistic conclusions. There is strong evidence that families do not behave as if they were a single economic agent, but this evidence is not incompatible with household efficiency. In fact, the identification strategy in the empirical literature on intrahousehold allocation often builds on the assumption that the household decision processes lead to efficient outcomes (e.g., Browning et al., 1994).

2 More generally, we may think of $X^{i}$ as a composite input incorporating many different market-produced goods. It is possible that some of these market-produced goods enter more than one household activity. The only substantive assumption needed for our purpose is the feasibility of selective taxation across different $X^{i}$,s. 
where $g^{i}(\cdot)$ features constant returns to scale and where $L_{P}^{i}$ and $L_{S}^{i}$ are the time inputs of the two household members, whom we will refer to as a primary $(P)$ and a secondary $(S)$ earner, respectively. The assumption of constant returns in home production simplifies the algebra considerably and is not as restrictive as it may seem. In particular, as explained later, the relevant previous studies are encompassed as special cases of our analysis. The formulation includes also cases where some activities use the time input of one household member only. If, say, activity 5 only uses input of the primary earner, then equation (2) becomes $L^{5}=a^{5} L_{P}^{5}$, where $a^{5}$ is some positive constant. On the other hand, we disregard the uninteresting case where one of the earners does not enter at all into any of the activities. In this case, the labor supply of the earner is perfectly inelastic and therefore optimal taxation becomes trivial.

Household decisions must be made in accordance with the budget constraint

$$
\sum_{i=1}^{n} P^{i} X^{i}-W_{P} N_{P}-N_{S} \leq 0,
$$

where $N_{P}$ and $N_{S}$ denote the labor supply to the market of the primary and the secondary earner, respectively, while $P^{i}$ is the consumer price of good $i$ and $W_{P}$ is the consumer wage of the primary worker. The consumer wage of the secondary worker is normalized to one $\left(W_{S}=1\right)$. Taxes are introduced by defining $P^{i} \equiv p^{i}+\tau^{i} P^{i}$ and $W_{P} \equiv w_{P}-\tau_{P} W_{P}$, where small letters refer to producer prices and wages, and where tax rates, $\tau^{i}$ and $\tau_{P}$, are measured as proportions of after-tax prices and wages. The government cannot use lump-sum taxes.

Since there is no lump-sum income in equation (3), two tax systems are equivalent if they differ only by a proportional tax on all commodities $X^{1}, \ldots, X^{n}, N_{P}, N_{S}$ (the budget constraint is homogeneous of degree zero in prices). Therefore, we gain an additional free normalization, and we set the tax rate on the secondary earner's income equal to zero (i.e., $W_{S}=w_{S}=1$ ). The tax rate $\tau_{P}$ should then be interpreted as the excess marginal tax rate on the primary earner's income, and $\tau_{P}=0$ corresponds to joint income taxation. In the interpretation of the results derived below, it will be important to keep in mind that this is just a normalization, not a restriction. The real restriction lies in the assumption, implicit in equation (3), that only market purchases are taxable, while household time is not. This corresponds exactly to the assumption made in the standard framework that labor is taxable while leisure is not. ${ }^{3}$

3 More generally, the restriction on the tax system - in our model as in the standard model - is that we cannot tax the consumption of any endowed commodity separately from its 
Decisions are also subject to the following time constraints of the two individuals:

$$
\sum_{i=1}^{n} L_{S}^{i}+N_{S}=1, \quad \sum_{i=1}^{n} L_{P}^{i}+N_{P}=1,
$$

where the total time available is normalized to one.

We solve the dual consumer problem by minimizing the LHS of (3) subject to $U \geq \bar{U}$ and equations (1), (2), and (4). The solution is characterized by

$$
\begin{aligned}
& \tilde{Z}^{i}=Z^{i}(\mathbf{Q}, \bar{U}) \text {, } \\
& \tilde{X}^{i}=x^{i}\left(P^{i}, W^{i}\right) \tilde{Z}^{i}, \quad \tilde{L}^{i}=l^{i}\left(P^{i}, W^{i}\right) \tilde{Z}^{i}, \\
& \tilde{L}_{P}^{i}=l_{P}^{i}\left(W_{P}\right) \tilde{L}^{i}, \quad \tilde{L}_{S}^{i}=l_{S}^{i}\left(W_{P}\right) \tilde{L}^{i},
\end{aligned}
$$

where a tilde refers to compensated demand or supply; $x^{i}$ and $l^{i}$ are the inputs of goods and labor, respectively, per unit of commodity $i$; and $l_{P}^{i}$ and $l_{S}^{i}$ are the time uses of primary and secondary earners per unit of labor in activity $i$. The solution depends on unit costs in household activities, $\mathbf{Q}=\left(Q^{1}, \ldots, Q^{n}\right)$, as well as wage indices, $W^{i}$, which are given by

$$
\begin{aligned}
& Q^{i}=Q^{i}\left(P^{i}, W^{i}\right) \equiv P^{i} x^{i}\left(P^{i}, W^{i}\right)+W^{i} l^{i}\left(P^{i}, W^{i}\right), \\
& W^{i}=W^{i}\left(W_{P}\right) \equiv W_{P} l_{P}^{i}\left(W_{P}\right)+l_{S}^{i}\left(W_{P}\right) .
\end{aligned}
$$

In the case where one of the activities only uses input of, say, the primary earner, it follows that $l_{P}^{i}=1$ and $l_{S}^{i}=0$.

For later use, note that the expenditure function may be derived by inserting equations (4) to (9) in equation (3), which gives

$$
e\left(\mathbf{Q}, W_{P}, \bar{U}\right)=\sum_{i=1}^{n} Q^{i} \tilde{Z}^{i}-W_{P}-1 .
$$

Becker's (1965) paper and the subsequent applications of his framework (e.g., Atkinson and Stern, 1980, 1981; Kleven, 2004) focused on the case of a fixed-coefficients (Leontief) consumption technology, i.e., $x^{i}\left(P^{i}, W^{i}\right) \equiv x^{i}$ and $l^{i}\left(P^{i}, W^{i}\right) \equiv l^{i}$. Initially, we focus on this case too, but in section 5 we consider the implications of allowing for substitution between goods and time in each activity. It should be noticed, however, that the assumption of fixed coefficients does not have to rule out the possibility of substitution in household production. Basic to the notion of any production function is the existence of different production processes, where each process uses a certain fixed ratio of inputs. A production function, in other words, is a description of substitution possibilities between production processes. In this 
interpretation, we may think of the $Z$-commodities as production processes, while the function $U$ captures the possibilities for substitution between these processes. ${ }^{4}$

Moreover, under the fixed-coefficients consumption technology, the effects of taxation on behavior are comparable to the effects discussed in the literature. Taxes affect behavior in two ways. Firstly, commodity and labor taxes induce a substitution away from goods-intensive activities towards time-intensive activities, thereby reducing the supply of labor to the market. This is analogous to the labor-leisure distortion of the Boskin-Sheshinski approach. Secondly, different marginal tax rates on the two household members affect the primary-secondary labor input mix in each household activity, corresponding to the effect introduced by the Piggott-Whalley contribution. Thus, the assumption of fixed coefficients retains the tax effects emphasized in the previous papers. Moreover, our framework is sufficiently general to encompass these studies as special cases. ${ }^{5}$

\section{Optimal Taxation}

To derive the optimal tax system, we define the dead-weight burden of taxation as the equivalent variation minus the tax revenue, that is,

$$
D=e\left(\mathbf{Q}, W_{P}, \bar{U}\right)-e\left(\mathbf{q}, w_{P}, \bar{U}\right)-T\left(\mathbf{P}, W_{P}, \bar{U}\right),
$$

where $\mathbf{q}=\left(q^{1}, \ldots, q^{n}\right)$ is the vector of unit costs in the absence of taxation, $\mathbf{P}=\left(P^{1}, \ldots, P^{n}\right)$ is the vector of consumer prices, $\bar{U}$ is the after-tax utility level, and $T(\cdot)$ is the total tax revenue defined as

$$
T\left(\mathbf{P}, W_{P}, \bar{U}\right)=\sum_{i=1}^{n}\left(P^{i}-p^{i}\right) \tilde{X}^{i}+\left(w_{P}-W_{P}\right) \tilde{N}_{P} .
$$

4 For example, dishwashing may be carried out by the use of a brush or a machine. These two production processes involve fixed (but different) ratios between time and market goods. Washing up with a brush and with a machine are then modeled as two different $Z$-commodities, while the substitution between them lies in the function $U$. Besides this substitution between production processes involving different proportions of goods and time, there is the possibility of substitution between the wife's and the husband's time (either one can do the dishes, or they can do them together). This type of substitution is modeled in the function $g^{i}(\cdot)$ in equation (2).

5 This is easily seen by considering the following examples: For $n=3$ and $l^{1}=x^{2}=l_{S}^{2}=x^{3}=l_{P}^{3}=0$, the utility function becomes $U\left(X^{1}, L_{P}^{2}, L_{S}^{3}\right)$, such that the framework corresponds to Boskin and Sheshinski (1983). For $n=4$ and $l^{1}=x^{2}=x^{3}=l_{S}^{3}=x^{4}=l_{P}^{4}=0$, the utility function becomes $U\left(X^{1}, g^{2}\left(L_{P}^{2}, L_{S}^{2}\right), L_{P}^{3}, L_{S}^{4}\right)$, such that the framework corresponds to Piggott and Whalley (1996). 
By inserting equations (4) to (9), the tax revenue becomes

$$
T\left(\mathbf{P}, W_{P}, \bar{U}\right)=\sum_{i=1}^{n}\left(P^{i}-p^{i}\right) x^{i} \tilde{Z}^{i}+\left(w_{P}-W_{P}\right)\left(1-\sum_{i=1}^{n} l_{P}^{i} l^{i} \tilde{Z}^{i}\right) .
$$

Given the usual assumption of linear production technology in the market sector, the optimal tax system may be found by minimizing $D$ with respect to consumer prices $\mathbf{P}$, and wages $W_{P}$, subject to an exogenous revenue requirement, $T\left(\mathbf{P}, W_{P}, \bar{U}\right) \geq \bar{T}$. By solving this problem and letting $\alpha_{X}^{i} \equiv x^{i} P^{i} / Q^{i}$ denote the cost share for market-produced goods in the production of commodity $i$, we obtain

Proposition 1 If goods shares are positive in all activities, $\alpha_{X}^{i}>0 \forall i$, then the optimal tax system is characterized by joint taxation, $\tau_{P}=0$, and the commodity tax structure $\tau^{i} / \tau^{j}=\alpha_{X}^{j} / \alpha_{X}^{i} \forall i, j$.

\section{Proof. See appendix 8.1.}

Thus, when all utility-yielding commodities require the input of market goods, it is more efficient to have joint than individual filing. ${ }^{6}$ To grasp the intuition, consider a situation with a uniform commodity tax and a joint (uniform) income tax. The presence of commodity taxation (increasing goods prices) and income taxation (lowering shadow wages) distorts relative unit costs in household activities, $Q^{i} / Q^{j}$, by making goods-intensive activities more expensive relative to time-intensive activities. This induces a substitution away from goods-intensive activities, thereby reducing the supply of labor to the market. Now, rather than using selective income taxation to deal with this distortion, it is better to employ selective commodity taxation. In particular, by imposing higher tax rates on goods that are used in time-intensive activities, as reflected by the rule in proposition 1, we keep relative unit costs unchanged, whereby distortions between household activities are avoided altogether. With an undistorted pattern of household activities, there is also no distortion of labor supply. In this situation, the use of individual income taxation, by changing relative shadow wages, merely creates a household production inefficiency, which could be avoided by the use of joint taxation. ${ }^{7}$

6 As explained previously, since the tax system is defined only up to a proportionality factor, we may normalize the tax rate on the secondary earner's income to zero. Accordingly, proposition 1 does not state that income tax rates should be zero, but that income tax rates should be identical for the primary and the secondary earner. As always in optimal taxation, there is a multitude of optima, each of them characterized by the same relative structure but different tax levels. One of these optima involves zero income taxation for both husband and wife, while others involve positive (or negative) tax rates on both partners.

7 For a more elaborate discussion of optimal commodity taxation in the Becker framework see Kleven (2004). 
At first glance, our result seems to resemble the production-efficiency theorem of Diamond and Mirrlees (1971a) stating that the optimal tax system retains production efficiency in the market sector as long as there are no privately received economic profits and provided that there are no restrictions on the use of commodity taxes. Analogously, our result shows that, once the optimal commodity-tax system is in place, we do not wish to introduce production inefficiencies within the household sector. There is a fundamental difference between the two propositions, however, in that the Diamond-Mirrlees result is a statement about a second-best tax system, while we have identified a first-best optimal tax system.

The assumption in proposition 1 that the optimal commodity tax structure can be implemented is a critical one. With nonoptimal commodity taxes there will be distortions in the pattern of household activities, which in turn implies a distortion of labor supply. In this case one might want to introduce selective individual income taxation to alleviate this labor-supply distortion. The next section looks into this matter.

\section{Restrictions on the Use of Commodity Taxes}

In practice, the use of optimal commodity taxes is obstructed by the presence of administrative costs, imperfect information, and political inefficiencies. In fact, such constraints could be even more important in our context than usual, because of the production-process interpretation discussed in section 2 . In this interpretation, there would be a large number of activities in the utility function and hence a large number of different commodity tax rates. This is not likely to be implementable. For example, one would imagine that the tax rate is restricted to be uniform within certain groups of commodities. Alternatively, some market goods might be untaxable, implying that the activities using these goods also become untaxed. We now wish to explore the consequences of these and other restrictions on the use of commodity taxes for the optimal tax treatment of the family.

For this purpose, we consider some exogenously given commodity tax structure $\left\{\tau^{i}\right\}_{i=1}^{n}$. In this tax structure, all goods might be taxed nonoptimally. More generally, a number of goods, say $m$, could be taxed optimally, while the tax rates on the remaining $n-m$ goods were set to some suboptimal levels. For this given nonoptimal commodity tax structure, we now ask whether it is possible to improve welfare through a marginal restructuring of the tax system that introduces different marginal tax rates on primary and secondary earners. Due to the equivalence of a uniform commodity tax and a uniform income tax, we may examine the consequence for welfare formally by, say, raising $\tau_{P}$ and making a uniform reduction of the $\tau^{i}$ s. 
Let $\eta^{k i} \equiv\left(\partial \tilde{Z}^{k} / \tilde{Z}^{k}\right) /\left(\partial Q^{i} / Q^{i}\right)$ denote the elasticity of compensated demand for activity $k$ with respect to the unit cost in activity $i$. Then, we have

Proposition 2 Consider a tax system characterized by a given commodity tax structure $\left\{\tau^{i}\right\}_{i=1}^{n}$ and joint taxation $\tau_{P}=0$. This tax system may be improved by a revenue-neutral change of tax rates on primary and secondary earners such that

$$
\operatorname{sign}\left\{\tau_{P}\right\}=\operatorname{sign}\left\{-\sum_{k=1}^{n}\left[\frac{\tilde{L}_{P}^{k}}{\tilde{N}_{P}}-\frac{\tilde{L}_{S}^{k}}{\tilde{N}_{S}}\right] \sum_{i=1}^{n} \eta^{k i} \tau^{i} \alpha_{X}^{i}\right\} .
$$

Proof. See appendix 8.2.

Note first that if all commodity taxes are at their first-best levels, then, as in proposition 1 , joint taxation is optimal. That is, $\tau_{P}=0$ when $\tau^{i} \alpha_{X}^{i}=$ $\tau^{j} \alpha_{X}^{j}$ for all $i, j$, since $\sum_{i=1}^{n} \eta^{k i}=0$ due to the homogeneity of degree zero of compensated demands. When the commodity tax rates are not at their optimal levels, individual taxation is typically optimal. However, the elements that determine the optimal sign of $\tau_{P}$ are different from those in the laborleisure analyses and do not lead to a general presumption in favor of a higher tax rate on primary earners.

To come to grips with proposition 2 , consider the special case where exactly one market good is untaxable whereas the remaining commodities are taxed according to the optimal tax rule in proposition $1 .^{8}$ By setting $\tau_{1}=0$ and $\tau^{i} \alpha_{X}^{i}=\tau^{j} \alpha_{X}^{j}$ for $i, j=2, \ldots, n$ in the above expression, we obtain

$$
\operatorname{sign}\left\{\tau_{P}\right\}=\operatorname{sign}\left\{\sum_{k=1}^{n}\left(\frac{\tilde{L}_{P}^{k}}{\tilde{N}_{P}}-\frac{\tilde{L}_{S}^{k}}{\tilde{N}_{S}}\right) \eta^{k 1}\right\} .
$$

Thus, we should impose a relatively low tax rate on the person whose time input is used mainly in combination with the untaxable good 1 as well as its complements. This rule reflects the fact that selective income taxation tries to compensate for the missing commodity-tax instrument. The specific restriction that we impose implies that activity 1 (and complementary activities) are taxed too leniently. To counteract this distortion, income taxation should be designed to raise shadow wages in these activities. This is done through

8 Notice that this special case may alternatively be thought of as the situation with pure leisure. For optimal-taxation purposes, the case where one activity is pure leisure is equivalent to the case where this activity uses market inputs that cannot be taxed. The substantive feature in both cases is the presence of an untaxable activity. Clearly, the case of untaxable activities is interesting, since in practice tax authorities may find it difficult to tax activities such as conversation with friends, caring for an infant, etc. Notice finally that even in the case of one untaxable activity (pure leisure) our framework differs from the labor-leisure framework, because the remaining activities require both market goods and household time as inputs. 
the imposition of low rates on the household member used intensively in these activities. ${ }^{9}$

Going back to the general case in proposition 2, we conclude that the person whose time input is used intensively in combination with market goods that are taxed too leniently, relative to the rule in proposition 1, should face the lower marginal tax rate. On the other hand, if there is no systematic correlation between time intensities and the activities that are taxed too leniently, selective income taxation cannot be used to compensate for inefficient commodity taxation. In any case, whether the income tax ought to favor the primary or the secondary earner (or neither) depends in the end on the nature of the administrative costs.

\section{Substitution Between Market Goods and Time}

So far, we have focused on the case of fixed technological coefficients for market goods and time in household activities. This assumption has been made in previous applications of the Becker framework, and it may be justified from a production-process interpretation of activities. However, as discussed in the previous section, this justification for the Leontief specification makes the incorporation of restricted commodity taxation more urgent than usual. Hence, an alternative to introducing restricted commodity taxation would be to drop the fixed-coefficients specification. In this section, we generalize the analysis to allow for substitution between market goods and time as well as restricted commodity taxation.

Let $\sigma_{Z}^{k}$ denote the (numerical) elasticity of substitution between time and market goods in activity $k$. Then proposition 2 generalizes to

Proposition 3 Consider a tax system characterized by a given commodity tax structure $\left\{\tau^{i}\right\}_{i=1}^{n}$ and joint taxation $\tau_{P}=0$. This tax system may be improved by a revenue-neutral change of tax rates on primary and secondary earners such that

$$
\operatorname{sign}\left\{\tau_{P}\right\}=\operatorname{sign}\left\{-\sum_{k=1}^{n}\left(\frac{\tilde{L}_{P}^{k}}{\tilde{N}_{P}}-\frac{\tilde{L}_{S}^{k}}{\tilde{N}_{S}}\right)\left(\sum_{i=1}^{n} \eta^{k i} \tau^{i} \alpha_{X}^{i}+\sigma_{Z}^{k} \tau^{k} \alpha_{X}^{k}\right)\right\} .
$$

Proof. See appendix 8.2.

The last term in the second parenthesis is new. The new term reflects that the commodity tax system creates an incentive for the family to substitute nontaxed time for taxed market goods in household activities. The

9 The introduction of selective income taxation also generates a distortion in the relative time use of the two partners in household production. However, this effect is irrelevant for the optimal sign of $\tau_{P}$, as it is only of second order when starting from a situation with identical rates. 
distortionary effect is particularly large in activities with a high degree of substitution between market goods and time and in activities with large goods shares. Now, if these activities mainly use primary labor, then it is possible to counteract the distortion by increasing the opportunity cost of using primary labor in the home. In this case, the couples should face a selective tax system with the lowest rate on the primary earner.

Proposition 3 considers a given commodity tax structure. We now turn to the case where commodity taxes are set optimally. Because of the substitutability between market goods and time in household production, the optimal tax rule is considerably more complicated than in proposition 1 . In order to simplify the analysis and focus entirely on the new effects, we disregard substitution between activities, i.e., $\eta^{k i}=0 \forall k, i$. We then derive the optimal commodity tax structure and substitute it into the condition in proposition 3. This gives (see appendix 8.3)

$$
\operatorname{sign}\left\{\tau_{P}\right\}=\operatorname{sign}\left\{-\sum_{k=1}^{n}\left(\frac{\tilde{L}_{P}^{k}}{\tilde{N}_{P}}-\frac{\tilde{L}_{S}^{k}}{\tilde{N}_{S}}\right) \frac{\alpha_{X}^{k}}{1-\alpha_{X}^{k}}\right\} .
$$

Interestingly, this equation shows that the optimization of the commodity tax system removes the importance of substitution elasticities for the sign of $\tau_{p}$. Only factor shares matter for the efficient differentiation of income tax rates. In particular, the tax system should favor the spouse whose time is used more in activities requiring a high share of market-produced goods.

\section{The Role of Labor-Supply Elasticities}

According to the standard reasoning, a selective income tax favoring the secondary earner is good for efficiency because it exploits the fact that the (compensated) labor supply of secondary earners is relatively elastic. In the context of our model, it is natural to ask if this empirical observation still provides an argument for choosing individual taxation.

To address this question, we derive the (compensated) labor-supply elasticity of the two household members. For the primary worker, the elasticity equals (see appendix 8.4)

$$
\frac{\partial \tilde{N}_{P} / \tilde{N}_{P}}{\partial W_{P} / W_{P}}=\sum_{k=1}^{n} \frac{\tilde{L}_{P}^{k}}{\tilde{N}_{P}}\left[\sigma_{L}^{k}\left(1-\alpha_{P}^{k}\right)+\sigma_{Z}^{k} \alpha_{P}^{k} \alpha_{X}^{k}-\sum_{i=1}^{n} \eta^{k i} \alpha_{L}^{i} \alpha_{P}^{i}\right],
$$

where $\sigma_{L}^{k}$ denotes the elasticity of substitution between the time uses for the husband and wife in activity $k, \sigma_{Z}^{k}$ denotes the elasticity of substitution between goods and time in activity $k, \alpha_{L}^{k}$ denotes the cost share for labor in activity $k$, and $\alpha_{P}^{k}$ denotes the share of labor costs attributed to the primary earner. The corresponding labor-supply elasticity for the secondary 
earner may be found by substituting $S$ for $P$ in the respective subscripts. Equation (15) shows that a wage increase for the primary earner raises his/her labor supply by inducing a substitution from primary-earner time to secondary-earner time in each household activity (first term in the bracket), by inducing a substitution from time to market goods in each activity (second term in the bracket), and by inducing a substitution away from the activities using a lot of primary time (third term in the bracket).

A comparison of equation (15) and the condition in proposition 3 shows that knowledge of labor-supply elasticities alone is insufficient to determine whether selective income taxation should favor secondary earners. The observed difference in labor-supply elasticities may for example be due to different shares in labor costs $\left(\alpha_{P}^{i}\right.$ and $\left.\alpha_{S}^{i}\right)$, but these parameters do not enter the condition provided by proposition 3 . Therefore, economic efficiency may, at least in principle, call for the lower tax rate on primary earners although their labor supply is relatively inelastic.

\section{Conclusion}

According to the conventional view, individual taxation is more efficient than joint taxation because the labor supply of secondary earners is more elastic than that of primary earners. However, this proposition relies on the labor-leisure model, which does not take into account that utility-yielding commodities take the form of activities using the input of both goods and time. Once we recognize this feature of household behavior, it turns out that selective commodity taxation, rather than selective income taxation, may be the best instrument to deal with the distortion of labor supply. Indeed, in the absence of restrictions on the use of commodity taxes, joint income taxation is optimal. With restrictions on the use of commodity taxes individual taxation is typically optimal, although not in the usual way. The income tax should try to compensate for the missing instruments, and consequently the differentiation of tax rates between primary and secondary earners depends on the nature of the administrative costs. In particular, there is no obvious relationship with labor-supply elasticities, and it may be optimal to favor primary earners even if their labor supply is relatively inelastic. Thus, the efficiency argument in favor of individual taxation with high marginal rates on primary earners may be more fragile than previously thought.

An issue not touched upon is the adverse effect of joint taxation on marriage decisions. In a progressive tax system, the tax liability of two unmarried people living together is generally different from that of a married couple filing jointly. Couples may face marriage subsidies or marriage penalties, depending on the distribution of income between spouses and on the con- 
struction of rate schedules. This may lead to distortions in marriage decisions; see, e.g., Alm and Whittington $(1997,1999)$.

Finally, it should be emphasized that the analysis has focused exclusively on efficiency, although the choice of tax unit may have important distributional implications as well. In particular, the tax treatment of couples raises issues pertaining to both intrafamily distribution (Apps and Rees, 1999b) and interfamily distribution (Kleven, Kreiner, and Saez, 2006). Before drawing firm policy conclusions, one should of course take account of such effects.

\section{Appendix}

\subsection{Proof of Proposition 1}

From the first-order conditions, we get the following conditions for the optimal tax system:

$$
\frac{\partial D}{\partial P^{j}} \frac{\partial T}{\partial W_{P}}=\frac{\partial D}{\partial W_{P}} \frac{\partial T}{\partial P^{j}}, \quad j=1, \ldots, n .
$$

Using (4), (11), $\partial e / \partial Q^{j}=\tilde{Z}^{j}$, and Shephard's lemma, we have

$$
\begin{aligned}
\frac{\partial D}{\partial P^{j}} & =\frac{\partial e}{\partial Q^{j}} \frac{\partial Q^{j}}{\partial P^{j}}-\frac{\partial T}{\partial P^{j}}=\tilde{Z}^{j} x^{j}-\frac{\partial T}{\partial P^{j}}, \\
\frac{\partial D}{\partial W_{P}} & =\sum_{k=1}^{n} \frac{\partial e}{\partial Q^{k}} \frac{\partial Q^{k}}{\partial W_{k}} \frac{\partial W_{k}}{\partial W_{P}}-1-\frac{\partial T}{\partial W_{P}}=-\tilde{N}_{P}-\frac{\partial T}{\partial W_{P}} .
\end{aligned}
$$

Inserting these derivatives in the above optimality conditions, we get

$$
-\frac{\partial T / \partial W_{P}}{\tilde{N}_{P}}=\frac{\partial T / \partial P^{j}}{\tilde{Z}^{j} x^{j}}, \quad j=1, \ldots, n,
$$

i.e., marginal revenue as a proportion of tax bases must be equal for all taxes.

From equation (12) and the definition of the tax rates, we obtain the derivatives

$$
\begin{aligned}
\frac{\partial T}{\partial P^{j}}= & \sum_{i=1}^{n} \tau^{i} P^{i} x^{i} \frac{\partial \tilde{Z}^{i}}{\partial Q^{j}} x^{j}+x^{j} \tilde{Z}^{j}-\tau_{P} W_{P} \sum_{i=1}^{n} l_{P}^{i} l^{i} \frac{\partial \tilde{Z}^{i}}{\partial Q^{j}} x^{j} . \\
\frac{\partial T}{\partial W_{P}}= & \sum_{i=1}^{n} \tau^{i} P^{i} x^{i} \sum_{k=1}^{n} \frac{\partial \tilde{Z}^{i}}{\partial Q^{k}} l^{k} l_{P}^{k}-\tilde{N}_{P} \\
& -\tau_{P} W_{P}\left(\sum_{i=1}^{n} l_{P}^{i} l^{i} \sum_{k=1}^{n} \frac{\partial \tilde{Z}^{i}}{\partial Q^{k}} l^{k} l_{P}^{k}+\sum_{i=1}^{n} \frac{\partial l_{P}^{i}}{\partial W_{P}} l^{i} \tilde{Z}^{i}\right),
\end{aligned}
$$


where we have used Shephard's lemma. Insertion of these derivatives in (16) yields

$$
\begin{aligned}
& \tilde{Z}^{j} \sum_{i=1}^{n} \tau^{i} P^{i} x^{i} \sum_{k=1}^{n} \frac{\partial \tilde{Z}^{i}}{\partial Q^{k}} l^{k} l_{P}^{k}+\tilde{N}_{P} \sum_{i=1}^{n} \tau^{i} P^{i} x^{i} \frac{\partial \tilde{Z}^{i}}{\partial Q^{j}} \\
& =\tau_{P} W_{P}\left[\tilde{N}_{P} \sum_{i=1}^{n} l_{P}^{i} l^{i} \frac{\partial \tilde{Z}^{i}}{\partial Q^{j}}+\tilde{Z}^{j} \sum_{i=1}^{n} l_{P}^{i} l^{i} \sum_{k=1}^{n} \frac{\partial \tilde{Z}^{i}}{\partial Q^{k}} l^{k} l_{P}^{k}+\tilde{Z}^{j} \sum_{i=1}^{n} \frac{\partial l_{P}^{i}}{\partial W_{P}} l^{i} \tilde{Z}^{i}\right] .
\end{aligned}
$$

Joint taxation is characterized by $\tau_{P}=0$. Thus, joint taxation is optimal if there exists $\left\{\tau^{i}\right\}_{i=1}^{n}$ such that the LHS of the above condition is equal to zero. This implies

$$
\tilde{Z}^{j} \sum_{k=1}^{n} l^{k} l_{P}^{k} \sum_{i=1}^{n} \tau^{i} P^{i} x^{i} \frac{\partial \tilde{Z}^{k}}{\partial Q^{i}}+\tilde{N}_{P} \sum_{i=1}^{n} \tau^{i} P^{i} x^{i} \frac{\partial \tilde{Z}^{j}}{\partial Q^{i}}=0,
$$

where we have used the symmetry of the Slutsky matrix. Using the definition $\alpha_{X}^{i} \equiv x^{i} P^{i} / Q^{i}$ and rearranging terms, we obtain

$$
\tilde{Z}^{j} \sum_{k=1}^{n} l^{k} l_{P}^{k} \sum_{i=1}^{n} \tau^{i} \alpha_{X}^{i} \frac{\partial \tilde{Z}^{k}}{\partial Q^{i}} Q^{i}+\tilde{N}_{P} \sum_{i=1}^{n} \tau^{i} \alpha_{X}^{i} \frac{\partial \tilde{Z}^{j}}{\partial Q^{i}} Q^{i}=0, \quad j=1, \ldots, n .
$$

As $\tilde{Z}^{j}$ is homogeneous of degree zero, implying that $\sum_{i=1}^{n}\left(\partial \tilde{Z}^{j} / \partial Q^{i}\right) Q^{i}=0$, it is now obvious that a solution to these first-order conditions is characterized by $\tau^{i} / \tau^{j}=\alpha_{X}^{j} / \alpha_{X}^{i}$ for $i, j=1, \ldots, n$. Thus, these formulae and $\tau_{P}=0$ characterize a solution to the optimal-tax problem.

\subsection{Proof of Proposition 2 and Proposition 3}

Proposition 3 generalizes proposition 2 by including substitution effects between goods and time in home production. A proof of proposition 3 is therefore also a proof of proposition 2 .

For a given initial commodity tax structure $\left\{\tau^{i}\right\}_{i=1}^{n}$, we consider the effect on the dead-weight loss of a marginal increase in $\tau_{P}$ and a corresponding reduction in a value-added tax rate, $\tau$, which keeps the tax revenue constant. The value-added tax is proportional to producer prices, giving rise to consumer prices $P^{i}=p^{i}(1+\tau) /\left(1-\tau^{i}\right)$. The effect on the dead-weight loss of a marginal change in these tax rates is given by

$$
\Psi\left(\tau_{P}, \tau\right)=\frac{\partial D\left(\tau, \tau_{P}\right)}{\partial \tau_{P}}+\frac{\partial D\left(\tau, \tau_{P}\right)}{\partial \tau} \frac{d \tau}{d \tau_{P}},
$$

where $d \tau / d \tau_{P}$ is the change in $\tau$ that keeps the tax revenue fixed. From $T\left(\tau, \tau_{P}\right)=\bar{T}$ we get $d \tau / d \tau_{P}=-\left[\partial T\left(\tau, \tau_{P}\right) / \partial \tau_{P}\right] /\left[\partial T\left(\tau, \tau_{P}\right) / \partial \tau\right]$, implying

$$
\Psi\left(\tau_{P}, \tau\right)=\frac{\partial D\left(\tau, \tau_{P}\right)}{\partial \tau_{P}}-\frac{\partial D}{\partial \tau} \frac{\partial T\left(\tau, \tau_{P}\right) / \partial \tau_{P}}{\partial T\left(\tau, \tau_{P}\right) / \partial \tau} .
$$


Using equations (4) and (11), we have

$$
\begin{aligned}
& \frac{\partial D\left(\tau, \tau_{P}\right)}{\partial \tau}=\sum_{j=1}^{n} \frac{\partial e}{\partial Q^{j}} \frac{\partial Q^{j}}{\partial P^{j}} \frac{\partial P^{j}}{\partial \tau}-\frac{\partial T}{\partial \tau}=\sum_{j=1}^{n} \tilde{Z}^{j} x^{j} \frac{p^{j}}{1-\tau^{j}}-\frac{\partial T}{\partial \tau}, \\
& \frac{\partial D\left(\tau, \tau_{P}\right)}{\partial \tau_{P}}=\sum_{k=1}^{n} \frac{\partial e}{\partial Q^{k}} \frac{\partial Q^{k}}{\partial W_{k}} \frac{\partial W_{k}}{\partial W_{P}} \frac{\partial W_{P}}{\partial \tau_{P}}-\frac{\partial W_{P}}{\partial \tau_{P}}-\frac{\partial T}{\partial \tau_{P}}=W_{P} \tilde{N}_{P}-\frac{\partial T}{\partial \tau_{P}},
\end{aligned}
$$

where the last equalities in the two expressions follow from $\partial e / \partial Q^{j}=\tilde{Z}^{j}$, Shephard's lemma, $\partial P^{i} / \partial \tau=p^{i} /\left(1-\tau^{i}\right)$, and $\partial W_{P} / \partial \tau_{P}=-W_{P}$. Inserting these expressions in $\Psi\left(\tau_{P}, \tau\right)$ gives

$$
\Psi\left(\tau_{P}, \tau\right)=W_{P} \tilde{N}_{P}-\frac{\partial T\left(\tau, \tau_{P}\right) / \partial \tau_{P}}{\partial T\left(\tau, \tau_{P}\right) / \partial \tau} \sum_{j=1}^{n} \tilde{Z}^{j} x^{j} \frac{p^{j}}{1-\tau^{j}} .
$$

On the presumption that $\partial T / \partial \tau>0$, i.e., the economy is on the upwardsloping part of the Laffer curve, it follows that $\Psi(0,0)>0$ if

$$
\frac{\partial T(0,0)}{\partial \tau} W_{P} \tilde{N}_{P}-\frac{\partial T(0,0)}{\partial t_{P}} \sum_{j=1}^{n} \tilde{Z}^{j} x^{j} P^{j}>0 .
$$

From equation (12) we obtain the derivatives of the tax function evaluated around the initial equilibrium:

$$
\begin{aligned}
& \frac{\partial T}{\partial \tau}(0,0)=\sum_{j=1}^{n}\left(x^{j}+\tau^{j} P^{j} \frac{\partial x^{j}}{\partial P^{j}}\right) \tilde{Z}^{j} P^{j}+\sum_{i=1}^{n} \tau^{i} P^{i} x^{i} \sum_{k=1}^{n} \frac{\partial \tilde{Z}^{i}}{\partial Q^{k}} P^{k} x^{k}, \\
& \frac{\partial T}{\partial \tau_{P}}(0,0)=-\sum_{i=1}^{n} \tau^{i} P^{i} x^{i} \sum_{k=1}^{n} \frac{\partial \tilde{Z}^{i}}{\partial Q^{k}} l^{k} l_{P}^{k} W_{P}-\sum_{i=1}^{n} \tau^{i} P^{i} \tilde{Z}^{i} \frac{\partial x^{i}}{\partial W^{i}} l_{P}^{i} W_{P}+W_{P} \tilde{N}_{P},
\end{aligned}
$$

where we have used Shephard's lemma, $\partial P^{i} / \partial \tau=P^{i}, P^{i}-p^{i}=\tau^{i} P^{i}$, and $\partial W_{P} / \partial \tau_{P}=-W_{P}$. After using symmetry of the Slutsky matrix and $\partial \tilde{Z}^{i} / \partial Q^{k}=$ $\partial \tilde{Z}^{k} / \partial Q^{i}$, as well as the relationships $l_{P}^{i} i^{i} \tilde{Z}^{i}=\tilde{L}_{P}^{i}, x^{i} \tilde{Z}^{i}=\tilde{X}^{i}, \alpha_{X}^{i} \equiv P^{i} x^{i} / Q^{i}$, and $W^{i} l^{i} / Q^{i}=1-\alpha_{X}^{i}$, the above derivatives may be rewritten as

$$
\begin{aligned}
\frac{\partial T}{\partial \tau}(0,0)= & \sum_{i=1}^{n}\left(1+\tau^{i} \frac{\partial x^{i} / x^{i}}{\partial P^{i} / P^{i}}\right) P^{i} \tilde{X}^{i}+\sum_{i=1}^{n} \tau^{i} \alpha_{X}^{i} \sum_{k=1}^{n} \frac{\partial \tilde{Z}^{k} / \tilde{Z}^{k}}{\partial Q^{i} / Q^{i}} P^{k} \tilde{X}^{k}, \\
\frac{\partial T}{\partial \tau_{P}}(0,0)= & -\sum_{i=1}^{n} \tau^{i} \alpha_{X}^{i} \sum_{k=1}^{n} \frac{\partial \tilde{Z}^{k} / \tilde{Z}^{k}}{\partial Q^{i} / Q^{i}} \tilde{L}_{P}^{k} W_{P} \\
& -\sum_{i=1}^{n} \tau^{i} \frac{\alpha_{X}^{i}}{1-\alpha_{X}^{i}} \tilde{L}_{P}^{i} \frac{\partial x^{i} / x^{i}}{\partial W^{i} / W^{i}} W_{P}+W_{P} \tilde{N}_{P} .
\end{aligned}
$$


In these two expressions, we substitute

$$
\begin{aligned}
& \eta^{k i} \equiv \frac{\partial \tilde{Z}^{k} / \tilde{Z}^{k}}{\partial Q^{i} / Q^{i}}, \quad \frac{\partial x^{i} / x^{i}}{\partial P^{i} / P^{i}}=-\left(1-\alpha_{X}^{i}\right) \sigma_{Z}^{i}, \\
& \text { and } \frac{\partial x^{i} / x^{i}}{\partial W^{i} / W^{i}}=\left(1-\alpha_{X}^{i}\right) \sigma_{Z}^{i},
\end{aligned}
$$

where $\sigma_{Z}^{k}$ denotes the (numerical) elasticity of substitution between $X^{i}$ and $L^{i}$. This gives

$$
\begin{aligned}
& \frac{\partial T}{\partial \tau}(0,0)=\sum_{i=1}^{n}\left[1-\tau^{i}\left(1-\alpha_{X}^{i}\right) \sigma_{Z}^{i}\right] P^{i} \tilde{X}^{i}+\sum_{i=1}^{n} \tau^{i} \alpha_{X}^{i} \sum_{k=1}^{n} \eta^{k i} P^{k} \tilde{X}^{k}, \\
& \frac{\partial T}{\partial \tau_{P}}(0,0)=-\sum_{i=1}^{n} \tau^{i} \alpha_{X}^{i} \sum_{k=1}^{n} \eta^{k i} \tilde{L}_{P}^{k} W_{P}-\sum_{i=1}^{n} \tau^{i} \alpha_{X}^{i} \tilde{L}_{P}^{i} \sigma_{Z}^{i} W_{P}+W_{P} \tilde{N}_{P} .
\end{aligned}
$$

After inserting these derivatives in (17), we obtain the condition

$$
\begin{aligned}
& \sum_{i=1}^{n} \sum_{k=1}^{n} \tau^{i} \alpha_{X}^{i} \eta^{k i}\left(\frac{P^{k} \tilde{X}^{k}}{\sum_{j=1}^{n} P^{j} \tilde{X}^{j}}+\frac{\tilde{L}_{P}^{k}}{\tilde{N}_{P}}\right) \\
& +\sum_{i=1}^{n} \tau^{i} \alpha_{X}^{i} \sigma_{Z}^{i}\left(\frac{\tilde{L}_{P}^{i}}{\tilde{N}_{P}}-\frac{Q^{i} \tilde{Z}^{i}-P^{i} \tilde{X}^{i}}{\sum_{j=1}^{n} P^{i} \tilde{X}^{j}}\right)>0,
\end{aligned}
$$

where we have used the definition of $\alpha_{X}^{i}$ in order to obtain the expression in the last bracket. Using equation (3) and equations (6) through (9), the condition may be written as

$$
\begin{aligned}
& \sum_{i=1}^{n} \tau^{i} \alpha_{X}^{i}\left[\sum_{k=1}^{n} \eta^{k i}\left(\frac{Q^{k} \tilde{Z}^{k}-W_{P} \tilde{L}_{P}^{k}-W_{S} \tilde{L}_{S}^{k}}{W_{P} \tilde{N}_{P}+W_{S} \tilde{N}_{S}}+\frac{\tilde{L}_{P}^{k}}{\tilde{N}_{P}}\right)\right. \\
& \left.+\sigma_{Z}^{i}\left(\frac{\tilde{L}_{P}^{i}}{\tilde{N}_{P}}-\frac{W_{P} \tilde{L}_{P}^{i}+W_{S} \tilde{L}_{S}^{i}}{W_{P} \tilde{N}_{P}+W_{S} \tilde{N}_{S}}\right)\right]>0,
\end{aligned}
$$

which, after multiplying by $\left(W_{P} \tilde{N}_{P}+W_{S} \tilde{N}_{S}\right) /\left(\tilde{N}_{S} W_{S}\right)$, becomes

$$
\sum_{i=1}^{n} \tau^{i} \alpha_{X}^{i}\left[\sum_{k=1}^{n} \eta^{k i}\left(\frac{Q^{k} \tilde{Z}^{k}}{W_{S} \tilde{N}_{S}}-\frac{\tilde{L}_{S}^{k}}{\tilde{N}_{S}}+\frac{\tilde{L}_{P}^{k}}{\tilde{N}_{P}}\right)+\sigma_{Z}^{i}\left(\frac{\tilde{L}_{P}^{i}}{\tilde{N}_{P}}-\frac{\tilde{L}_{S}^{i}}{\tilde{N}_{S}}\right)\right]>0 .
$$

Symmetry of the Slutsky matrix and homogeneity of degree zero of the compensated demand functions give the following relationship:

$$
\sum_{k=1}^{n} \eta^{k i} \frac{Q^{k} \tilde{Z}^{k}}{W_{S} \tilde{N}_{S}}=\sum_{k=1}^{n} \frac{\partial \tilde{Z}^{k}}{\partial Q^{i}} Q^{i} \frac{Q^{k}}{W_{S} \tilde{N}_{S}}=\frac{Q^{i}}{W_{S} \tilde{N}_{S}} \sum_{k=1}^{n} \frac{\partial \tilde{Z}^{i}}{\partial Q^{k}} Q^{k}=0,
$$

which implies that the above inequality may be stated as

$$
\sum_{k=1}^{n}\left(\frac{\tilde{L}_{P}^{k}}{\tilde{N}_{P}}-\frac{\tilde{L}_{S}^{k}}{\tilde{N}_{S}}\right)\left(\sum_{i=1}^{n} \tau^{i} \alpha_{X}^{i} \eta^{k i}+\tau^{k} \alpha_{X}^{k} \sigma_{Z}^{k}\right)>0 .
$$


Thus, a small increase in $\tau_{P}$ and a corresponding reduction in $\tau$ increase the dead-weight loss if this inequality is fulfilled, and vice versa. Proposition 2 arises as the special case where $\sigma_{Z}^{k}=0 \forall k$.

\subsection{Derivation of Equation (14)}

We start by finding the optimal commodity tax rates when $\tau_{P}=0$. That is, we solve

$$
\min _{P^{1}, \ldots, P^{n}} D\left(P^{1}, \ldots, P^{n}, W_{P}, \bar{U}\right) \quad \text { s.t. } \quad T\left(P^{1}, \ldots, P^{n}, W_{P}, \bar{U}\right) \geq \bar{T},
$$

where $D(\cdot)$ is the dead-weight burden of taxation while $T(\cdot)$ denotes government revenue. The first-order conditions are

$$
\frac{\partial D / \partial P^{k}}{\partial T / \partial P^{k}}=\mu, \quad k=1, \ldots, n,
$$

where $\mu$ is the shadow price associated with the government budget constraint. From equation (11), $\partial e / \partial Q^{k}=\tilde{Z}^{k}$, and Shephard's lemma, we have

$$
\frac{\partial D}{\partial P^{k}}=\frac{\partial e}{\partial Q^{k}} \frac{\partial Q^{k}}{\partial P^{k}}-\frac{\partial T}{\partial P^{k}}=\tilde{Z}^{k} x^{k}-\frac{\partial T}{\partial P^{k}} .
$$

This relationship is substituted into the above optimality conditions, which gives

$$
\frac{\tilde{Z}^{k} x^{k}}{\partial T / \partial P^{k}}=1+\mu
$$

From equation (12), the definition of the tax rates, and the assumption of no substitution between activities, i.e., $\partial \tilde{Z}^{i} / \partial Q^{k}=0$, we obtain the derivative

$$
\frac{\partial T}{\partial P^{k}}=x^{k} \tilde{Z}^{k}+\left(P^{k}-p^{k}\right) \tilde{Z}^{k} \frac{\partial x^{k}}{\partial P^{k}},
$$

where we have used Shephard's lemma. Insertion of this derivative in the above condition gives the optimal commodity tax rates

$$
\tau^{k}=\frac{1}{\sigma_{Z}^{k}} \frac{1}{1-\alpha_{X}^{k}} \frac{\mu}{1+\mu},
$$

where we have used $P^{k}-p^{k}=\tau^{k} P^{k}, \alpha_{X}^{k} \equiv P^{k} x^{k} / Q^{k}$, and $\left(\partial x^{k} / x^{k}\right) /$ $\left(\partial P^{k} / P^{k}\right)=-\left(1-\alpha_{X}^{k}\right) \sigma_{Z}^{k}$. Finally, by combining this expression with proposition 3 and the assumption $\eta_{k i}=0$, we obtain equation (14).

\subsection{Derivation of Equation (15)}

The labor supply of the primary worker follows from equations (4) to (7):

$$
\tilde{N}_{P}=1-\sum_{k=1}^{n} \tilde{L}_{P}^{k}=1-\sum_{k=1}^{n} l_{P}^{k}\left(W_{P}\right) l^{k}\left(P^{k}, W^{k}\right) Z^{k}\left(Q^{1}, \ldots, Q^{n}, \bar{U}\right),
$$


implying that

$$
\begin{aligned}
\frac{\partial \tilde{N}_{P}}{\partial W_{P}}= & -\sum_{k=1}^{n} \frac{\partial l_{P}^{k}}{\partial W_{P}} l^{k} \tilde{Z}^{k}-\sum_{k=1}^{n} l_{P}^{k} \frac{\partial l^{k}}{\partial W^{k}} \frac{\partial W^{k}}{\partial W_{P}} Z^{k} \\
& -\sum_{k=1}^{n} \sum_{i=1}^{n} l_{P}^{k} l^{k} \frac{\partial \tilde{Z}^{k}}{\partial Q^{i}} \frac{\partial Q^{i}}{\partial W^{i}} \frac{\partial W^{i}}{\partial W_{P}} \\
= & -\sum_{k=1}^{n} \frac{\partial l_{P}^{k} / l_{P}^{k}}{\partial W_{P} / W_{P}} \frac{\tilde{L}_{P}^{k}}{W_{P}}-\sum_{k=1}^{n} l_{P}^{k} \frac{\partial l^{k} / l^{k}}{\partial W^{k} / W^{k}} \frac{\tilde{L}_{P}^{k}}{W^{k}} \\
& -\sum_{k=1}^{n} \sum_{i=1}^{n} \tilde{L}_{P}^{k} \frac{\partial \tilde{Z}^{k} / \tilde{Z}^{k}}{\partial Q^{i} / Q^{i}} \frac{l^{i} l_{P}^{i}}{Q^{i}},
\end{aligned}
$$

where the last equality follows from Shepard's lemma and $\tilde{L}_{P}^{k}=l_{P}^{k} l^{k} \tilde{Z}^{k}$. Now, the labor-supply elasticity may be written as

$$
\begin{aligned}
\frac{\partial \tilde{N}_{P} / \tilde{N}_{P}}{\partial W_{P} / W_{P}}=\sum_{k=1}^{n} \frac{\tilde{L}_{P}^{k}}{\tilde{N}_{P}} & -\frac{\partial l_{P}^{k} / l_{P}^{k}}{\partial W_{P} / W_{P}}-\frac{\partial l^{k} / l^{k}}{\partial W^{k} / W^{k}} \frac{W_{P} l_{P}^{k}}{W^{k}} \\
& \left.-\sum_{i=1}^{n} \frac{\partial \tilde{Z}^{k} / \tilde{Z}^{k}}{\partial Q^{i} / Q^{i}} \frac{W^{i} l^{i}}{Q^{i}} \frac{W_{P} l_{P}^{i}}{W^{i}}\right) .
\end{aligned}
$$

Inserting

$$
\begin{aligned}
\frac{\partial l_{P}^{k} / l_{P}^{k}}{\partial W_{P} / W_{P}}=-\left(1-\alpha_{P}^{k}\right) \sigma_{L}^{k}, & \frac{W_{P} l_{P}^{k}}{W^{k}}=\alpha_{P}^{k}, \\
\frac{\partial l^{k} / l^{k}}{\partial W^{k} / W^{k}}=-\left(1-\alpha_{L}^{k}\right) \sigma_{Z}^{k}, & \frac{W^{k} l^{k}}{Q^{k}}=\alpha_{L}^{k}, \quad \text { and } \quad \eta^{k i}=\frac{\partial \tilde{Z}^{k} / \tilde{Z}^{k}}{\partial Q^{i} / Q^{i}},
\end{aligned}
$$

we obtain equation (15).

\section{References}

Alm, J., and Whittington, L. A. (1997), Income Taxes and the Timing of Marital Decisions, Journal of Public Economics 64, 219-240.

Alm, J., and Whittington, L. A. (1999), For Love or Money? The Impact of Income Taxes on Marriage, Economica 66, 297-316.

Apps, P. F., and Rees, R. (1999a), Individual versus Joint Taxation in Models with Household Production, Journal of Political Economy 107, 393-403.

Apps, P. F., and Rees, R. (1999b), On the Taxation of Trade within and between Households, Journal of Public Economics 73, 241-263.

Atkinson, A. B., and Stern, N. H. (1980), On the Switch from Direct to Indirect Taxation, Journal of Public Economics 14, 195-224. 
Atkinson, A. B., and Stern, N. H. (1981), On Labour Supply and Commodity Demands, in: Deaton, A. S. (ed.), Essays in the Theory and Measurement of Consumer Behavior, Cambridge University Press, Cambridge, 265-296.

Auerbach, A. J. (1985), The Theory of Excess Burden and Optimal Taxation, in: Auerbach, A. J., and Feldstein, M. (eds.), Handbook of Public Economics, vol. I, North Holland, Amsterdam, 61-128.

Becker, G. S. (1965), A Theory of the Allocation of Time, Economic Journal 75, 493-517.

Boskin, M. J., and Sheshinski, E. (1983), Optimal Tax Treatment of the Family: Married Couples, Journal of Public Economics 20, 281-297.

Browning, M., Bourguignon, F., Chiappori, P., and Lechene, V. (1994), Income and Outcomes: A Structural Model of Intrahousehold Allocation, Journal of Political Economy 102, 1067-1096.

Chiappori, P. (1992), Collective Labour Supply and Welfare, Journal of Political Economy $100,437-4 \overline{67 .}$

Diamond, P. A., and Mirrlees, J. A. (1971a), Optimal Taxation and Public Production I: Production Efficiency, American Economic Review 61, 8-27

Diamond, P. A., and Mirrlees, J. A. (1971b), Optimal Taxation and Public Production II: Tax Rules, American Economic Review 61, 261-278.

Gottfried, P., and Richter, W. F. (1999), The Tax Unit and Household Production: Comment, Journal of Political Economy 107, 404-409.

Gronau, R. (1973), The Intrafamily Allocation of Time: The Value of the Housewives' Time, American Economic Review 68, 634-651.

Gronau, R. (1977), Leisure, Home Production, and Work: The Theory of the Allocation of Time Revisited, Journal of Political Economy 85, 1099-1123.

Kleven, H. J. (2004), Optimum Taxation and the Allocation of Time, Journal of Public Economics 88, 545-557.

Kleven, H. J., and Kreiner, C. T. (2005), Labor Supply Behavior and the Design of Tax and Transfer Policy, Danish Journal of Economics 143, 321-358.

Kleven, H. J., Kreiner, C. T., and Saez, E. (2006), The Optimal Income Taxation of Couples, NBER Working Paper 12685.

Lundberg, S., Pollak, R., and Wales, T. (1997), Do Husbands and Wives Pool Their Resources? Evidence from the United Kingdom Child Benefit, Journal of Human Resources 32, 463-504.

Piggott, J., and Whalley, J. (1996), The Tax Unit and Household Production, Journal of Political Economy 104, 398-418.

Rosen, H. S. (1977), Is It Time to Abandon Joint Filing?, National Tax Journal 30, 423-428.

\section{Claus Thustrup Kreiner \\ Department of Economics \\ University of Copenhagen \\ Studiestræde 6 \\ DK-1455 Copenhagen K \\ Denmark \\ ctk@econ.ku.dk}

